\title{
Spray Ignition and Local Flow Properties in a Swirled Confined Spray-Jet Burner: Experimental Analysis
}

\author{
J. Marrero-Santiago ${ }^{\star 1}$, A. Verdier ${ }^{1}$, A. Vandel ${ }^{1}$, G. Godard ${ }^{1}$, G. Cabot ${ }^{1}$, B. Renou ${ }^{1}$ \\ ${ }^{1}$ Normandie Univ, INSA Rouen, UNIROUEN, CNRS, CORIA, 76000 Rouen, France \\ ${ }^{*}$ Corresponding author: marreroj@coria.fr
}

\begin{abstract}
Laser ignition was investigated in the swirled, confined CORIA Rouen Spray Burner under ultra-lean conditions $(\phi=0.61)$ with $n$-heptane as the liquid fuel. Ignition probability was calculated for different spark locations and compared to the non-ignited local flow properties. Mean velocity components of the carrier flow were measured by PDA under spray presence and without spray, and are compared to mean values from PIV. PIV measurements provide information on the instantaneous airflow and the total strain rate. Fuel droplet size-velocity data was measured by PDA. Toluene-PLIF images were acquired to provide information on the local equivalence ratio and the flammability factor. Results show that the outer recirculation zone (ORZ) has a flammability factor close to 1 and the highest ignition probability $(\sim 80 \%)$. These results have a high correlation with the air velocity field and turbulent kinetic energy. Instantaneous equivalence ratio images and shear rate-velocity fields give important information on local segregation of the flow properties that help to understand the ignition process. The present work provides a useful database for numerical simulations and industry, plus new insight on spray ignition.
\end{abstract}

\section{Keywords}

Spray ignition, PDA, PIV, Toluene PLIF, Ignition probability, Local flow properties.

\section{Introduction}

The ignition process in gas turbines involves a wide range of parameters which makes it a multi-physical complex problem. New aeronautical burner designs demand a better knowledge of the mechanisms here involved to assure, for instance, re-ignition in high altitude of lean-combustion engines. Real combustors work with two-phase flows with strongly varying local properties. Indeed, turbulence, flow velocity, droplet size and velocity, and fuel vapour repartition are parameters governing the ignition mechanisms. Several studies on spray ignition [1-3] have been carried out. Studies on spray ignition in industrial configurations are still scarce although some pioneer experiments and simulations in linear [4,5] and annular combustors [6, 7] have been done. Investigations on the influence of parameters such as turbulence $[8,9]$ also exist. The knowledge is still not sufficient to identify and understand the real mechanisms of ignition. More experiments are also needed to validate numerical simulations.

Ignition in aeronautical engines can be divided into four steps: (i) energy deposition through a spark and its evolution into a flame kernel; (ii) kernel propagation; (iii) flame stabilisation on one injector; (iv) injector-to-injector propagation of the flame. Sometimes one of these phases is not successful and leads to a missed ignition. Even with a sufficient energy supply at phase (i), phase (ii) appears to be a critical step, namely in lean conditions. During its propagation in the chamber, the flame kernel will be exposed to varying local properties of the flow that may be adverse for its survival. This depends on both, the initial location of the kernel (spark location) and on its subsequent trajectory. Ignition probability is, therefore, very important for designers and for numerical simulations.

The present investigation addresses the ignition of a mono-injector swirled confined jet-spray burner. An ignition probability map is obtained through a probabilistic approach varying the spark location inside the chamber. The gaseous flow velocity field is characterised by phase Doppler anemometry (PDA), as well as the fuel ( $n$-heptane) droplet distribution, size and velocity. High-speed particle image velocimetry (PIV) provides the gaseous instantaneous velocity fields. In order to complete the study of the local properties, the fuel vapour distribution is also measured by planar laser induced fluorescence (PLIF) on a tracer (toluene). This technique enables the simultaneous visualisation of the fuel droplets, the air issuing jet and the fuel vapour concentration in the gaseous phase, providing the local fuel-to-air equivalence ratio along all regions in the burner.

\section{Material and methods}

Facility

Experiments are carried out in a swirled version of the CORIA Rouen Spray Burner [10, 11], confined with quartz windows in order to allow full optical access (Fig.1). The system is composed of a simplex pressure atomizer (Danfoss, $1.46 \mathrm{kgh}^{-1}, 80^{\circ}$ hollow cone) and an external annular swirling air co-flow with an inner and outer diameter 
of 10 and $20 \mathrm{~mm}$ respectively. The radial swirler is composed of 18 rectangular $(6 \mathrm{~mm} \times 8 \mathrm{~mm})$ channels inclined at $45^{\circ}$ with a corresponding swirl number of 0.76 [12]. Air and liquid fuel ( $n$-heptane) mass flow rates are controlled by thermal and Coriolis mass flow controllers. The airflow leaves the annular pipe to enter the combustion chamber as a turbulent jet with a strong swirling motion establishing low pressures and a consequent recirculation region at the centre of the burner. The air and fuel inlet conditions are $8.2 \mathrm{gs}^{-1}\left(\mathrm{~T}=416 \pm 2 \mathrm{~K}\right.$ ) and $0.33 \mathrm{gs}^{-1}$ ( $\left.\mathrm{T} 350 \mathrm{~K}\right)$ respectively, leading to a global equivalence ratio $(\phi)$ of 0.61 representing ultra-lean conditions. The four windows form a chamber of $10 \mathrm{~cm} \times 10 \mathrm{~cm}$ base. Under these conditions, the system reaches a stable internal window temperature of $387 \mathrm{~K}$, which is constantly measured by a thermocouple to assure the repeatability of experiments. For the ignition experiment, the mixture is ignited with a laser induced spark, by focusing a $532 \mathrm{~nm}$ laser beam in a selected location inside the combustion chamber. Ignition details are provided at the end of the following section.
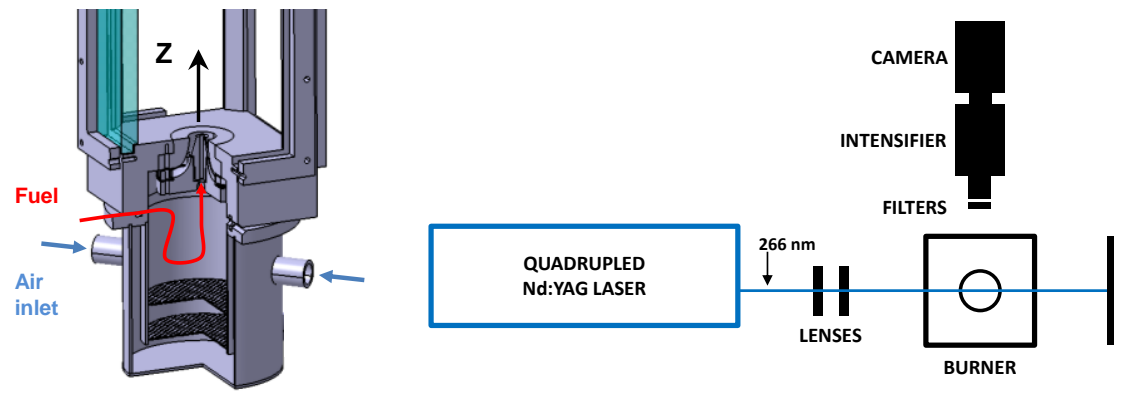

Figure 1. Cut of the burner with detail of the injection system and experimental setup for toluene-PLIF.

\section{Diagnostics}

All diagnostics were applied to the non-reactive flow in order to describe the local flow properties present in the burner at the moment of ignition.

- Phase Doppler anemometry (PDA):

Droplet size and velocity were measured by a commercial PDA system (DANTEC) operating in FIBER mode. An argon laser provided green $(514.5 \mathrm{~nm})$ and blue $(488 \mathrm{~nm})$ beams. Beam spacing was $50 \mathrm{~mm}$; transmitting and receiving lenses focal lengths were $350 \mathrm{~mm}$ and $310 \mathrm{~mm}$, respectively. The off-axis angle of the receiving optics was $50^{\circ}$ (in front scattering position), which is close to the Brewster angle. Laser energy before beam separation was $2 \mathrm{~W}$. The used aperture mask allows a detection diameter range of $139 \mu \mathrm{m}$. The measurement volume can be approximated by a cylinder of $120 \mu \mathrm{m}$ in diameter and $200 \mu \mathrm{m}$ in length. Data sampling was limited to 40,000 droplets or to $30 \mathrm{~s}$ of measuring time, allowing converged statistics of size-classified data. Due to the spray structure and particle concentration distribution, the measurements were not possible below $z=10 \mathrm{~mm}$. The gain and voltage in the photomultipliers (PMs) were adjusted so as not to saturate the anode currents in order to correctly detect the dispersed phase. The carrier phase velocity measurements were performed by seeding the air with $2 \mu \mathrm{m}$ olive oil droplets and increasing the gain and voltage in the PMs. Provided that the PDA system was 2D, only two velocity components (in the perpendicular direction to the interference fringes) could be measured simultaneously. PDA data are presented here through statistical estimators and the spray properties are assumed to be of rotational symmetry. Therefore, one radial profile reveals the axial and radial components of the velocity field and a second radial profile (perpendicular to the first one) reveals the axial (again) and azimuthal components.

- High-speed particle image velocimetry (HS-PIV):

It is also important to analyse the instantaneous airflow velocity fields given that the processes that are analysed in this paper are of a transitory and stochastic nature. For this purpose, the carrier phase was seeded far upstream with $<2 \mu \mathrm{m}$ zirconium oxide $\left(\mathrm{ZrO}_{2}\right)$ particles. Particle image velocimetry was applied on the airflow without spray presence at a $5 \mathrm{kHz}$ repetition rate on the $\mathrm{RZ}$ plane (vertical cut) with a magnification factor of $0.05 \mathrm{~mm} / \mathrm{px}$. A double cavity $527 \mathrm{~nm}$ Nd:YLF laser (Darwin Dual Quantronix) and a Phantom V2512 high-speed camera were used. The time between laser pulses was set to $7 \mu$ s enabling to correctly capture the wide range of velocities present in the flow and preventing the seeding particles from leaving the interrogation plane between pulses due to perpendicular velocity components (azimuthal). The confinement windows increase the complexity of the experiments enabling a short acquisition time before becoming covered by dust. 5000 raw single images were selected to calculate 2500 instantaneous vector fields. Raw images were normalised by their corresponding mean images to reduce any spatial energy variations and background scattering. The $1280 \times 800 \mathrm{px}^{2}$ images were processed with Dynamic Studio from DANTEC using the Adaptive PIV calculation, with initial and final interrogation windows of $64 \times 64$ and $16 \times 16 \mathrm{px}^{2}, 50 \%$ of overlap and a maximum iteration number of 10, yielding 159x99 vector fields. The signal-tonoise ratio acceptance was set over 1.5 and a $5 \times 5 \mathrm{px}^{2}$ median validation was applied. Post-processing with Matlab 
enabled to further analyse the data. The mean velocity field and the total strain rate field (instantaneous and mean) were calculated.

- Planar laser induced fluorescence (PLIF) on toluene:

Local equivalence ratio is a very important parameter in the ignition process. Its characterisation is, indeed, vital in order to understand the mechanisms that govern ignition. At these lean-mixture configurations slight equivalence ratio variations imply very big variations of the minimum ignition energy (MIE) [13]. PLIF on a tracer enabled to measure the molar fraction of fuel vapour and calculating the local gaseous equivalence ratio in the chamber. Toluene was selected as a tracer of the fuel vapour as it presents a boiling point $(383.75 \mathrm{~K})$ close to that of $n$ heptane $(371.57 \mathrm{~K})$. Figure 3 presents the experimental setup. Toluene was excited with a laser sheet at $266 \mathrm{~nm}$ by a quadrupled Nd-YAG laser at a repetition rate of $10 \mathrm{~Hz}$. The fluorescence light was collected by an intensified camera (EMICCD PIMAX 4) equipped with two $275 \mathrm{~nm}$ high-pass filters (ZUL275 x $1 \mathrm{~mm}$ ) and a $280 \mathrm{~nm}$ high-pass filter (WG280 x $3 \mathrm{~mm}$ ), so as to reduce the signal from droplets. The tracer was mixed at $2 \%$ in volume in the $n$ heptane reservoir.

Toluene is very sensitive to $\mathrm{O}_{2}$-quenching and its fluorescence signal $\left(\mathrm{S}_{\mathrm{f}}\right)$ varies with temperature. For this reason, a preliminary study of the dependence of $S_{f}$ on temperature variations (dT) was performed by varying the amount of $\mathrm{O}_{2}$ injected in the chamber. It was found that, for the nominal gas temperature $(\mathrm{T}=416 \pm 2 \mathrm{~K})$, a configuration with $1 \% \mathrm{O}_{2}$ and $99 \% \mathrm{~N}_{2}$ in mass (in the co-flow) nullifies the dependence of $\mathrm{S}_{\mathrm{f}}$ on $\mathrm{dT}$ for $\mathrm{dT}<15 \mathrm{~K}$. This agrees with the analysis performed in [14]. Therefore, the air inlet conditions for this experiment were modified to $0.4 \mathrm{gs}^{-1}$ of air and $7.8 \mathrm{gs}^{-1}$ of $\mathrm{N}_{2}$. In this way, $\mathrm{S}_{f}$ only depends on the molar concentration of toluene and, making the hypothesis that the fuel evaporates at the same rate under the new configuration, it provides useful information on the fuel vapour repartition. Raw images were normalized by a laser sheet mean image, recorded at the same flow conditions at the top part of the burner where droplets are no longer present. The mean noise image was subtracted from the raw images. 500 noise images were recorded at both burner locations; 1000 laser sheet images were acquired at the top part and 3000 raw images of the spray region (bottom) were acquired. This was performed on a $43 \times 43 \mathrm{~mm}$ field comprising one half zoom of the chamber. The laser sheet mean image is a reference of the molar concentration of toluene present in the fully evaporated homogeneous fuel-gas mixture. This allows performing the calculation of the fuel mixture fraction and of the equivalence ratio in the corrected images.

- Ignition probability exploration:

Ignition in the burner was addressed using a probabilistic approach. The mixture was ignited by a laser-induced spark in a selected location inside the burner using a focused $532 \mathrm{~nm}$ laser beam. A convergent lens of $200 \mathrm{~mm}$ focal length is used. The experimental setup is similar to the one used in [8]. The energy of the laser pulse was controlled and adjusted through the use of a coated variable dielectric attenuator (Laser Optik, Ref. 1Q2) without modifying the Q-switch delay in order to keep the physical beam properties constant. A chopper was used to operate in a single-shot mode. The deposited laser energy was around $405 \mathrm{~mJ}$. This high value is necessary to ensure a full dynamic range of ignition probability within the domain, due to very lean operating conditions $(\phi=0.61)$. The energy deposited in the spark was obtained from the measurements of the reference and transmitted laser pulse energies with two precision laser pyroelectric energy meters (Ophir: PE-25). The spark position was varied through a mesh of 132 interrogation points. For each spark position, 30 independent ignition tests were performed and ignition probability in each point was calculated dividing the number of successful events by the total test number. To make the experiment repeatable, it was crucial to keep the wall temperature constant. For this purpose, a thermocouple constantly measured the inner wall temperature ( $T=385 \mathrm{~K}$ in stable conditions with non-reacting flow). A Labview program permitted precise a control of the parameters and automatization of the process, triggering a spark only when the nominal conditions were reached. Time between sparks was $~ 20$ s.

\section{Results and discussion}

\section{Air velocity}

PDA data was post-processed to extract the mean components of the gaseous velocity field, the liquid Sauter mean diameter and size-classified velocity field. In this section, the mean gaseous velocity field is presented and compared to mean data from PIV measurements. The PIV instantaneous velocity fields are presented in second place.

- Mean velocity profiles (PDA vs PIV):

Figure 2 shows the axial (left), radial (middle) and azimuthal (right) mean velocity components of the airflow. Black dots represent the airflow velocity without spray presence (by PDA) and green triangles represent the airflow velocity with spray presence (by PDA). The PIV mean velocities (axial and radial) are stressed by the orange line. The global observation of the figure reveals that there is a very good agreement between all plots. This means that the spray induces minor modifications in the flow motion. A closer look at the axial velocities shows two peaks at $\mathrm{r}=10 \mathrm{~mm}\left(\sim 45 \mathrm{~ms}^{-1}\right)$ and central negative velocities $\left(\sim-23 \mathrm{~ms}^{-1}\right)$ due to the inner recirculation zone (IRZ), typical 
from swirling flows. Maximum velocities are observed at low axial stations $(\mathrm{z}=10 \mathrm{~mm})$ and relax downstream with a widening of the air jet. At $z=45 \mathrm{~mm}$, axial velocity ranges from -7 to $16 \mathrm{~ms}^{-1}$. Radial velocities present much lower values with maximum peaks of $\sim 10 \mathrm{~ms}^{-1}$ at $\mathrm{z}=10, \mathrm{r}=10 \mathrm{~mm}$, describing the lateral opening of the jet. Values show the same type of downstream relaxation. The outer recirculation zone (ORZ) is captured at $z=10 \mathrm{~mm}$ for $r>15 \mathrm{~mm}$ with small centripetal values. Azimuthal velocities show a narrow peak of $33 \mathrm{~ms}^{-1}$ at $z=10, r=8 \mathrm{~mm}$ that decreases to $10 \mathrm{~ms}^{-1}$ at $z=45, r=20 \mathrm{~mm}$. PIV measurements show a good agreement with PDA data.
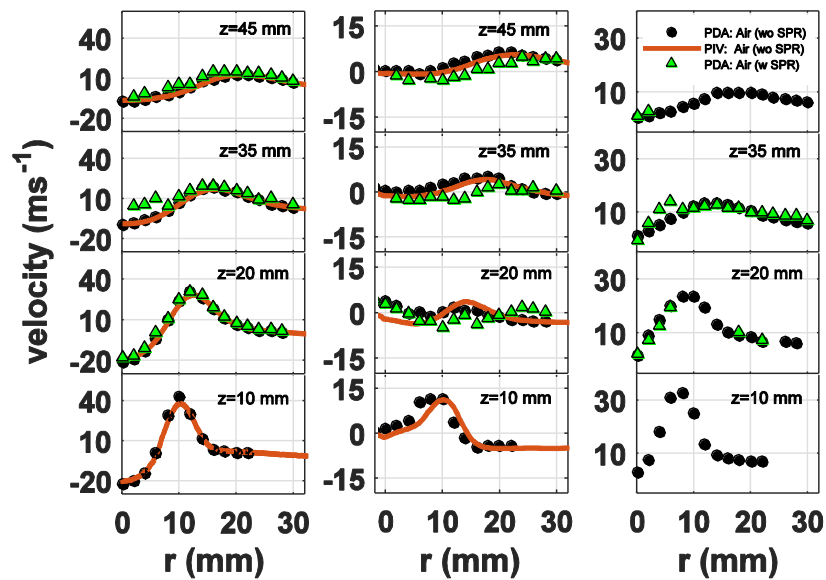

Figure 2. Mean components of air velocity. Left: axial; middle: radial; right: azimuthal. Black and green markers: PDA data without and with spray presence, respectively. Orange lines: PIV data without spray presence.

- Instantaneous velocity fields (PIV):

Instantaneous snapshots of the velocity field reveal more information of the gaseous behaviour. Figure 3 shows the vectors of three temporally independent instantaneous velocity fields. The colour map represents the total instantaneous strain rate $(\sigma)$ of the flow calculated from the 2D strain rate tensor, as shown in Fig.3. The real strain rate would take into account the third velocity component, but $2 \mathrm{D}$ data already adds some valuable information. Shearing structures are mostly generated in the highly turbulent region at the exit of the air duct, at low axial stations, where high velocities meet with movements in different directions (IRZ and ORZ). Some of these structures are transported by a global flow motion downstream and can be found at different points in the entire domain. The ORZ is generally free of high strain rates. Velocity fluctuations from one instant to another result in variations in the size of the IRZ and ORZ (i.e.: A vs C). Changes in velocity magnitude of the main jet structure can be also observed (i.e.: A vs B). These variations introduce significant differences in the behaviour of passive scalars present in the flow and in ignition mechanisms.

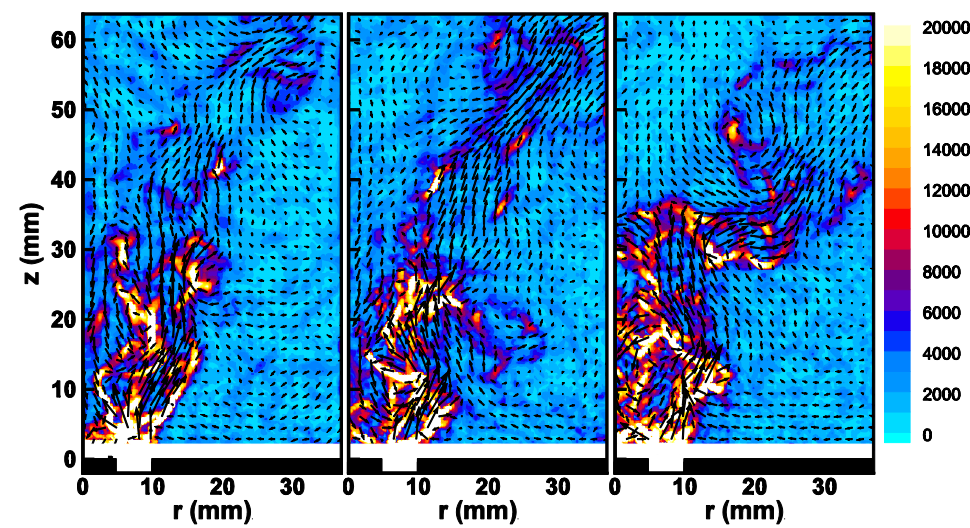

$$
\begin{gathered}
E_{i j}=\frac{1}{2}\left(\partial_{j} v_{i}+\partial_{i} v_{j}\right) \\
\sigma=\left(\sum E_{i j}^{2}\right)^{1 / 2}
\end{gathered}
$$

Figure 3. Instantaneous air velocity fields from PIV. Colours represent the total strain rate $\left(\mathrm{s}^{-1}\right)$.

\section{Fuel droplet size and velocity}

\section{- Sauter mean diameter and droplet distribution:}

The fuel spray presents a complex heterogeneous distribution, with droplet sizes ranging from 2 to $80 \mu \mathrm{m}$. The Sauter mean diameter (SMD) (Fig.4 (left)) takes values around $30 \mu \mathrm{m}$ and shows higher values at the borders of the spray $(\sim 35 \mu \mathrm{m})$ and lower values at the centre $(\sim 20 \mu \mathrm{m})$. This tendency is reproduced for all axial stations. The 
droplets are expelled from the atomizer with a strong radial component, forming a hollow cone of $80^{\circ}$ opening. Big droplets have ballistic trajectories whereas small droplets follow better the carrier flow motion, entering in the recirculation zones (IRZ and ORZ). This explains the lower SMD observed at the centre and at $Z=10 \mathrm{~mm}, \mathrm{r}>15 \mathrm{~mm}$. Figure 4 (right) presents the presence of droplets in the domain by the number of droplets detected per second by the PDA. A void can be observed at the centre, confirming the hollow nature of the cone. All size classes are distributed in the same way, meaning that a heterogeneous size mixture is present everywhere. The predominant size-classes are [10-20] and [20-30] $\mu \mathrm{m}$.
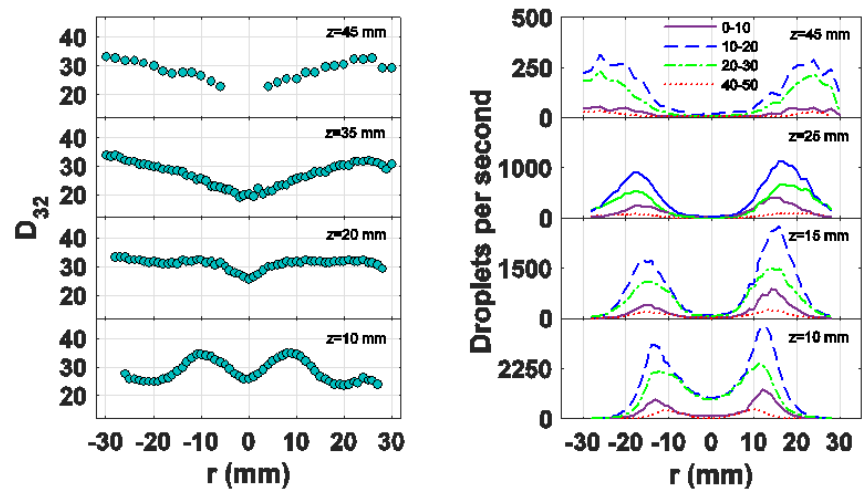

Figure 4. Left: Sauter mean diameter of the spray droplets. Right: droplet detection frequency by size classes.

\section{- Size-classified velocity:}

The three mean velocity components are shown in Figure 5 for three different size classes: [0-10], [20-30] and [4050] $\mu \mathrm{m}$. Values for the last group are not shown in the central region above $z=15 \mathrm{~mm}$ because less than 100 droplets were detected during the measurements. When comparing Figure 5 to Figure 2, it can be noticed that [0-10] $\mu \mathrm{m}$ droplets (named small droplets hereafter) follow more closely the airflow velocity field than [40-50] $\mu$ m droplets (named big droplets hereafter). The main difference with the air velocity is observed for the mean radial velocity profiles. Spray droplets are ejected from the nozzle with strong radial velocities. At the first axial station, the three groups have important radial velocities $\left(\sim 30 \mathrm{~ms}^{-1}\right)$ but farther downstream small droplets adapt their velocity to the airflow. Big droplets follow more ballistic trajectories and continue to present important radial centrifugal velocities until $z=35 \mathrm{~mm}$, where they nearly join the other groups. When overlapped to the air stream, droplet axial and azimuthal mean velocities are smaller for the spray than for the air, so small droplets are strongly accelerated by the co-flow while big droplets continue flying at smaller velocities until farther downstream. When fuel droplets exit the high air velocity region, the opposite occurs: they find a quiescent area where they still conserve a high axial velocity. This is more remarkable at low axial stations and for big droplets, and it is also observed for the azimuthal component to a lesser extent. Differences of more than $20 \mathrm{~ms}^{-1}$ are observed between the [0-10] group and the [4050] group.
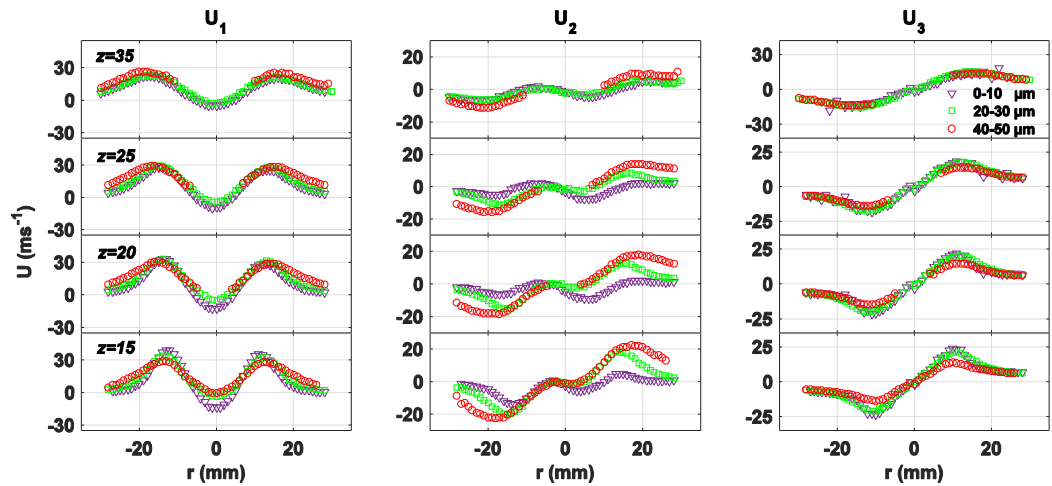

Figure 5. Mean components of fuel droplet velocity separated into three size classes. Left: axial; middle: radial; right: azimuthal.

The other size-classes present the same trends, but they are not presented here so as to facilitate the comprehension of the figure. The behaviour of [50-60] and [60-70] groups is very close to the [40-50] group, but, as they contain less droplets, they are not presented. During their trajectories, droplets experience important slip velocities, which certainly control the evaporation process and, therefore, vapour production and local air-to-fuel 
ratio. Slip velocities correspond to the relative velocities between droplets and the airflow. They are a key parameter in two-phase evaporation and combustion.

\section{Local gaseous equivalence ratio}

Toluene-PLIF corrected images represent the local equivalence ratio in the burner. A non-linear diffusion filter presented in [15] was applied on them so as to delete incoherent fluctuations at high spatial frequency coming from the camera noise. Figure 6 (left) shows an instantaneous filtered equivalence ratio image. Fuel droplets can be observed on the image. Indeed, there is a much higher tracer concentration in the liquid phase than in the gaseous phase. It was verified that $S_{f}$ has a linear response for gaseous equivalence ratios of $\phi<4.3$ and, through a calibration curve, this enabled to determine a threshold on top of which pixel values are rejected. These pixels and their neighbours are coloured in black on the image and are not taken into account for the further calculations, provided that the objective is to characterize the gaseous equivalence ratio. Some interesting observations can be extracted from Fig.6 (left). The droplet jet is coloured in red and big droplets in black. Droplets are expelled away from the nozzle at an angle to exit the image at the top right corner. Fuel droplets and high equivalence ratio zones near droplets are organized in the flow following a curvy pattern and around rotational structures in 1, 2 and 3, recalling, indeed, the airflow patterns observed in Fig.3. This type of preferential segregation was investigated in [16]. The core of the eddies in 1, 2 and 3 reveals low equivalence ratio values (below flammability limits $(\phi \sim 0.555$ [17])). Next to the dense spray, the airflow entrance can be observed in black and dark blue $(\phi \sim 0)$. The ORZ presents a homogeneous equivalence ratio close to the global equivalence ratio $(\phi \sim 0.61)$ whereas the IRZ shows lower values (below flammability limits sometimes). Figure 6 (middle) shows the mean equivalence ratio calculated from 3000 instantaneous images and reveals a similar $\phi$ distribution with a stoichiometric iso-line surrounding the mean spray branch. Points named $A$ to $F$ represent single-pixel probes used to extract $\phi$ PDFs in the 3000 instantaneous images. Histograms in Fig.6 (right) show the equivalence ratio PDFs at the probe positions. The IRZ shows an increase in equivalence ratio from $A$ to $B$. The majority of the PDS at point $A$ is beyond the flammability limits. Both points in the ORZ reveal constant values of $\phi$ inside the flammability limits. In contrast to these narrow histograms, PDFs in the spray branch range from $\phi \sim 0.5$ to $\phi \sim 4$ due to the alternation of rich and lean structures. As the probe moves towards the spray core ( $F$ to E), PDFs become wider and richer because the fuel is more concentrated.
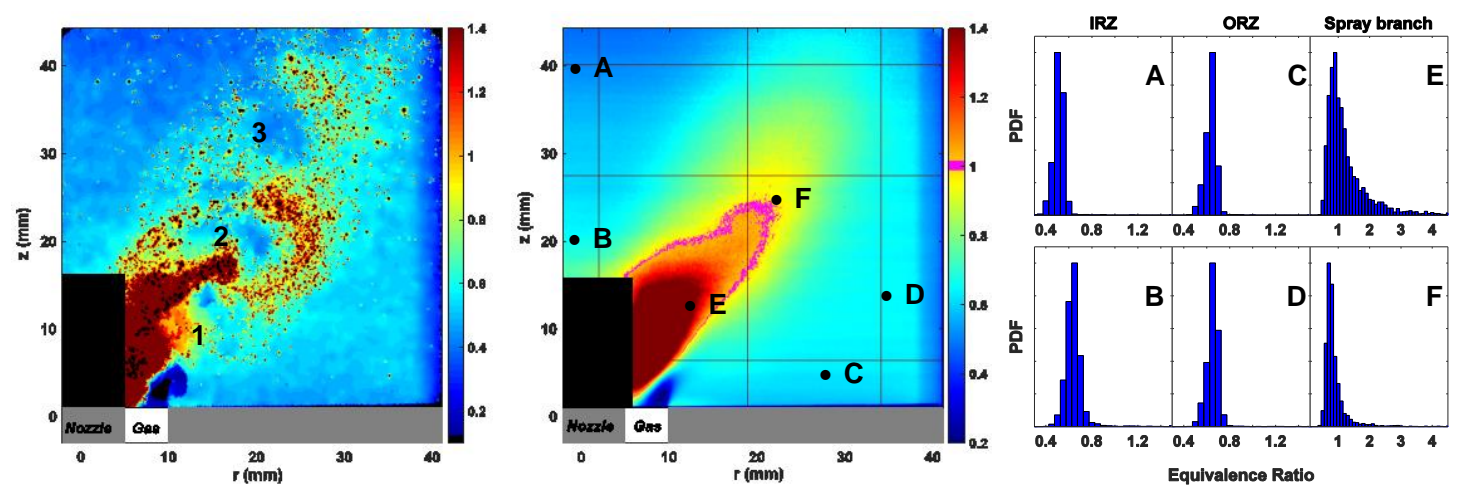

Figure 6. Left: instantaneous equivalence ratio image. Middle: mean equivalence ratio image. Right: Equivalence ratio PDFs at different probe positions ( $\mathrm{A}$ to $\mathrm{F}$ marked on the mean image).

The flammability factor $(F)$ is defined as the probability of finding a mixture between the low and high flammability limits $(0.555<\phi<2.008$ for $n$-heptane, calculated from [17]). Indeed, it corresponds to the area of the PDFs between these values. The reader can refer to the review done in [18]. The flammability factor was calculated for each pixel and it is presented in Fig.7 (left). It is here where the ORZ clearly stands out as the best ignitable zone, with $F$ values very close to 1 , meaning that the mixture is always ignitable here. The IRZ shows much lower values except near the spray $(z<20 \mathrm{~mm})$. The dense spray core and the air inlet present very low or zero $F$ and the mean spray branch can be identified as a region of lower $F$ than the ORZ.

Ignition probability

Ignition probability was evaluated in function of the spark location through the laser-induced ignition experiment. Figure 7 (right) indicates by black-magenta iso-contour lines the ignition probability map of the combustion chamber. Colour maps represent the turbulent kinetic energy $k$ and the velocity magnitude $|\mathrm{V}|$ of the airflow locally. The ignition probability map reveals that ignition becomes an impossible task in the centre of the burner (globally for $\mathrm{r}<20 \mathrm{~mm}$ ). There is a steep growth in probability from $r \sim 20$ to $r \sim 30 \mathrm{~mm}$ to reach a plateau of of $\sim 70$ and $\sim 80 \%$ in the ORZ close to the walls. Lean conditions ( $\left.\phi_{\text {global }} \sim 0.61\right)$ make ignition a very complicated task because the initial flame kernel is very vulnerable to any variations of the local flow properties and, depending on its initial location, it 
will be generated under very different flow conditions. The detailed description of the flow in the chamber reveals a very strong variation of local properties. This directly determines the trajectory of the flame kernel and whether it will survive or not. An analysis of the influence of the local flow properties is now presented.
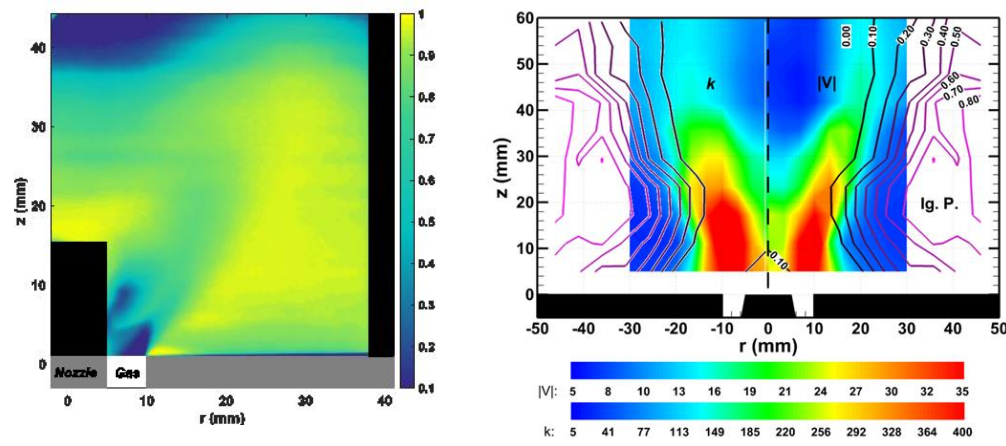

Figure 7. Left: Flammability factor. Right: Ignition probability map (lines); airflow turbulent kinetic energy " $k$ " $\left(m^{2} s^{-2}\right)$ and airflow velocity magnitude $|\mathrm{V}|\left(\mathrm{ms}^{-1}\right)$.

\section{- Comparison to local flow properties:}

During the kernel's initial life, its surrounding environment will quickly determine its properties (size, shape, wrinkling, reaction rate, temperature, growth rate, movement, etc.) and strongly condition the probability of establishing a stable flame on the injector. The trajectory of the flame kernel also has an important impact on ignition probability since it forces the kernel to change location, hence, flow properties. The cartography of ignition probability shown in Fig.7 (right) presents a very high correlation with the velocity magnitude $|\mathrm{V}|$ and the turbulent kinetic energy $k$, being the shape of the probability iso-lines the same as those of $|\mathrm{V}|$ and $k$. Ignition probability appears to be zero where velocity magnitude reaches $\sim 20 \mathrm{~ms}^{-1}$ and where $k$ reaches $\sim 250 \mathrm{~m}^{2} \mathrm{~s}^{-2}$, and it is very high when $|\mathrm{V}|$ and $k$ are very low. This is true for the $O R Z$ whereas the IRZ is not ignitable. Moreover, black-magenta iso-lines describe a typical ORZ shape. The flammability factor map explains why the IRZ has zero ignition probability: $F$ values are too low or reach acceptable values (at low axial stations) where $k$ starts to grow. The stoichiometric line in the mean equivalence ratio image (Fig.6 (middle)) shows no correlation with ignition probability because histograms in E and F (Fig.6 (right)) and the instantaneous $\phi$ (Fig.6 (left)) reflect the importance of the instantaneous mixture distribution. The latter demonstrates the stratified nature of the present lean mixture. When sparking in the spray branch region, local $\phi$ can be $\sim 0.5$ once and $\sim 4$ in the following instant of time, while the $O R Z$ always presents constant $\phi$ values. Figure 4 (right) shows that very few fuel droplets are still present beyond $r \sim 30$ $\mathrm{mm}$, where ignition probability grows. In fact, fuel droplets have antagonist effects on the kernel. On the one hand, they intensely supply fuel vapour elevating the equivalence ratio near the flame, thus, elevating laminar flame speeds, heat release and flame temperature (which is positive in a globally lean mixture). In contrast, fuel droplets are below their boiling temperature $(371.53 \mathrm{~K}$ for $n$-heptane) and evaporation implies a cooling of the fuel. This has a negative impact on the system, lowering the flame temperature by boosting heat dissipation from the flame front and from the burnt gases. In this sense, small, pre-evaporated droplets would perturb the flame to a lesser extent. The flame kernel is very vulnerable to strain too. Shear and vorticity affect the flame stretch and wrinkling. When the kernel enters a region with too much shear stress during its propagation, it is ripped and divided into smaller pieces. This can lead to misfire if the kernel is still too small due to an increase in surface and heat losses. Figure 3 reveals high strain rates in regions with low ignition probability. The ORZ is generally free of shearing structures, which are distributed along the main air jet trajectory in the surroundings of the ORZ. For $z>30$ and $r>20 \mathrm{~mm}$, high strain rates alternate with lower strain rates along the main jet. If the spark is triggered near a high strain rate location, the initial kernel may be suddenly teared until extinction or into several pieces. A second spark in the same location an instant later will possibly not find this shearing structure and ignition will be possibly successful. This explains that in regions with alternating properties ignition probability presents high variability. When a flame kernel is initiated in the ORZ, free from shearing flow movements, it will have the time and opportunity to develop and grow robust enough to support future strains and local extinctions.

\section{Conclusions}

Spray ignition was investigated under ultra-lean conditions through experiments to determine ignition probability against spark location (laser-induced) inside the swirled, confined CORIA Rouen Spray Burner. Local flow properties were characterised by advanced laser techniques. Phase Doppler anemometry (PDA) measurements informed on fuel droplet size, distribution and velocity and on airflow velocity. High-speed particle image velocimetry 
(PIV) enabled the description of the instantaneous gaseous velocity field and comparison to the mean data from PDA. Planar laser induced fluorescence (PLIF) on toluene as a tracer of $n$-heptane was used to characterise the local gaseous equivalence ratio throughout the burner.

The flammability factor $(F)$, extracted from the equivalence ratio images, reveals that the ORZ presents good ignitable properties, being $F \sim 1$ here. The ignition probability map, in accordance to $F$, shows that the ORZ is the best region to start a flame kernel in the present configuration, with $\sim 80 \%$ of success. The IRZ, on the opposite, is not appropriate to start ignition. Probability iso-lines reveal a steep increase at the interphase between the strong air jet and the start of the ORZ. A very high correlation is observed between the ignition probability and the air velocity and turbulent kinetic energy, finding high probabilities for low velocities and low turbulent kinetic energies. Equivalence ratio images describe the stratification of the mixture and explain why the IRZ is non-ignitable. Instantaneous PIV air velocity fields enable the calculation of local strain rates that also explain the survival or extinction of flame kernels, being the ORZ globally free of high shearing structures. Fuel droplets are mainly present in the spray branch and are rare in the IRZ and ORZ. The present work provides new insight on spray ignition and a detailed description of the local flow properties in a swirled confined jet-spray burner in non-reactive conditions. It is a useful database for industry and for the initialisation and validation of numerical simulations.

\section{Acknowledgements}

The authors acknowledge financial support from ANR under the project TIMBER ANR-14-CE23-0009.

\section{References}

[1] Marchione, T., Ahmed, S. F., and Mastorakos, E., 2009, "Ignition of turbulent swirling n-heptane spray flames using single and multiple sparks," Combustion and Flame, 156(1), pp. 166-180.

[2] Moesl, K. G., Vollmer, K. G., Sattelmayer, T., Eckstein, J., and Kopecek, H., 2009, "Experimental Study on Laser-Induced Ignition of Swirl-Stabilized Kerosene Flames," Journal of Engineering for Gas Turbines and Power, 131(2), pp. 021501-021508.

[3] Wandel, A. P., 2014, "Influence of scalar dissipation on flame success in turbulent sprays with spark ignition," Combustion and Flame, 161(10), pp. 2579-2600.

[4] Kao, Y.-H., Denton, M., Wang, X., Jeng, S.-M., and Lai, M.-C., 2015, "Experimental Spray Structure and Combustion of a Linearly-Arranged 5-Swirler Array," (56680), p. V04AT04A038.

[5] Cordier, M., Vandel, A., Renou, B., Cabot, G., Boukhalfa, A. M., Esclapez, L., Barré, D., Cuenot, B., and Gicquel, L., "Experimental and numerical analysis of an ignition sequence in a multiple-injectors burner, GT 2013 - 94681," Proc. Proceeding of the the ASME Turbo Expo.

[6] Prieur, K., Durox, D., Beaunier, J., Schuller, T., and Candel, S., 2017, "Ignition dynamics in an annular combustor for liquid spray and premixed gaseous injection," Proceedings of the Combustion Institute, 36(3), pp. 3717-3724.

[7] Machover, E., and Mastorakos, E., 2017, "Experimental investigation on spark ignition of annular premixed combustors," Combustion and Flame, 178, pp. 148-157.

[8] Cardin, C., Renou, B., Cabot, G., and Boukhalfa, A. M., 2013, "Experimental analysis of laser-induced spark ignition of lean turbulent premixed flames: New insight into ignition transition," Combustion and Flame, 160(8), pp. 1414-1427.

[9] Ahmed, S. F., Balachandran, R., Marchione, T., and Mastorakos, E., 2007, "Spark ignition of turbulent nonpremixed bluff-body flames," Combustion and Flame, 151(1-2), pp. 366-385.

[10] Shum-Kivan, F., Marrero Santiago, J., Verdier, A., Riber, E., Renou, B., Cabot, G., and Cuenot, B., 2017, "Experimental and numerical analysis of a turbulent spray flame structure," Proceedings of the Combustion Institute, 36(2), pp. 2567-2575.

[11] Verdier, A., Marrero Santiago, J., Vandel, A., Saengkaew, S., Cabot, G., Grehan, G., and Renou, B., 2017, "Experimental study of local flame structures and fuel droplet properties of a spray jet flame," Proceedings of the Combustion Institute, 36(2), pp. 2595-2602.

[12] Cordier, M., 2013, "PhD Thesis, Allumage et propagation de flamme dans les écoulements fortement swirlés : études expérimentales et numériques," CORIA, INSA de Rouen, France.

[13] Beduneau, J.-L., Kim, B., Zimmer, L., and Ikeda, Y., 2003, "Measurements of minimum ignition energy in premixed laminar methane/air flow by using laser induced spark," Combustion and Flame, 132(4), pp. 653-665.

[14] Rossow, B., 2011, "PhD Thesis, Processus photophysiques de molécules organiques fluorescentes et du kérosène applications aux foyers de combustion : applications aux foyers de combustion," Paris 11 , France.

[15] Xavier, P., Vandel, A., Godard, G., Renou, B., Grisch, F., Cabot, G., Boukhalfa, M. A., and Cazalens, M., 2016, "Investigation of combustion dynamics in a cavity-based combustor with high-speed laser diagnostics," Experiments in Fluids, 57(4), p. 50.

[16] Reveillon, J., and Demoulin, F.-X., 2007, "Effects of the preferential segregation of droplets on evaporation and turbulent mixing," Journal of Fluid Mechanics, 583, pp. 273-302.

[17] Neophytou, A., 2010, "PhD Thesis, Spark Ignition and Flame Propagation in Sprays," University of Cambridge, England.

[18] Mastorakos, E., 2009, "Ignition of turbulent non-premixed flames," Progress in Energy and Combustion Science, 35(1), pp. 57-97. 